\title{
Sustainable Electronics: Wireless Systems with Minimal Environmental Impact
}

\author{
David V. Thiel \\ Centre for Wireless Monitoring and Applications \\ Griffith University, Nathan Qld 4111 Australia. \\ d.thiel@griffith.edu.au
}

\begin{abstract}
Global warming, greenhouse gas emissions and ewaste are all major issues world-wide. Antennas are now a very common component in most consumer electronic devices (eg computers, telephones, toys, etc) in addition to wireless sensor networks and RFID systems used for product management and animal husbandry. In moving to RoHS and WEEE compliant systems, antenna engineers must consider new design methods and materials in antenna mass-manufacturing. Of course, minimal system energy use requires radiation efficiency and perhaps, electronic beam steering. This paper reports on the design and manufacture of antenna systems which greatly reduce the "carbon footprint" of wireless systems.
\end{abstract}

\section{INTRODUCTION}

Electronics manufacturers in Europe and exporters to Europe are now constrained by a number of directives including The Reduction of Hazardous Substances (RoHS) [1] and Waste from Electrical and Electronic Equipment (WEEE) [2]. The objective of these directives is e-waste management at product end-of-life. The total "carbon foot-print" in manufacturing includes manufacturing energy requirements and processing waste, energy minimisation during operation, and also the energy requirements for recycling or reuse. The United Nations sponsored organisation "Solving the E-waste Problem" (StEP) is an international consortium with partnerships between research institutes, tertiary education institutions and industry, formed to address the problems associated with current e-waste products manufactured before the new directives were enacted and generating new manufacturing technologies to minimise the impact of e-waste in future products [3].

Until recently, antenna engineers have been relatively immune from environmental concerns apart from radiation exposure close to radiating devices. The situation has changed because the number of antennas now in commercial and personal use has increased almost exponentially in the last twenty years, and the lifetime of such products has decreased dramatically. Current plans indicate an even greater increase in the use of wireless devices and so antenna designers must now pay significant attention to the environmental impact of these antennas and the energy requirements for manufacture and recycling and reuse. This paper addresses some of these issues and proposes some of the solutions for antenna design.

Traditionally antenna engineers have always played a part in energy use minimisation through wireless connections, improved radiation efficiency, directional antennas, integrated antennas and electrically configurable antennas as well as volume and area minimisation. Antenna optimisation now requires a more detailed look at such issues as the carbon footprint, materials selection, recycling strategies and reuse.

\section{Wireless CONSUMER PRODUCTS}

Until 30 years ago, very few consumer products had a requirement for wireless communications. Valve radios and later portable radios ('transistor radios') with telescopic whip antennas and ferrite multi-turn loop antennas were the first wireless consumer products. Television receivers used aluminium Yagi-Uda antennas, single wire loops or telescopic dipoles. These devices were built to have a usable life of 1030 years.

In the last 30 years there has been an explosion in radio communications associated with consumer products. The first products were remotely controlled toys, garage opening equipment, and keyless entry for motor vehicles. The next major growth area and still popular today are cellular (mobile) telephones, GPS navigation systems, wireless connectivity using blue tooth, and computers with wireless networking capability. Many of these devices have antennas printed on the electronic circuit board. An approximate time chart for consumer products with antennas is given in Table 1 . The volume production of almost all of these devices continues to increase very rapidly world-wide.

TABLE I

APPROXIMATE TIME CHART FOR CONSUMER ELECTRONICS WITH EMBEDDED ANTENNAS

\begin{tabular}{|l|l|l|}
\hline \multicolumn{1}{|c|}{ Year } & \multicolumn{1}{|c|}{ Product } & \multicolumn{1}{c|}{ Antenna } \\
\hline 1930 & Valve radio & Loop \\
\hline 1935 & Walkie-talkie & Whip \\
\hline 1950 & Transistor radio & Telescopic whip, ferrite loop \\
\hline 1965 & Television & Telescopic whip, Yagi-Uda \\
\hline 1980 & Key-less entry & Printed loop, wire whip \\
\hline 1970 & Toy cars & Whip \\
\hline 1985 & Mobile telephone & Patch, PIFA, monopole \\
\hline 1988 & Global Positioning & Patch, helix \\
\hline 1990 & Satellite television & Dish \\
\hline 1995 & Access cards & Printed loop \\
\hline 2000 & Blue tooth & Patch, PIFA, monopole \\
\hline 2002 & Computer wireless & PIFA, monopole, \\
\hline 2005 & RFID & Printed dipoles, slots, loops \\
\hline 2006 & Wireless Sensors & Printed loop, whip \\
\hline
\end{tabular}

978-1-4244-2193-0/08/\$25.00 @2008 IEEE 
The next major commercial advance is RFID identification systems. This technology has had extraordinary growth in both the retail industry and in manufacturing automation.

RFID is likely to replace bar-code scanning and so RFID antennas might soon be printed on every item in supermarkets and general stores, and every component in a manufacturing line. The RFID lifetime requirements for these products are equivalent to the product shelf-life and so often have a very short lifetime (often less than one month). RFID tags are used in distance scanning of everything from bed-sheets in hospitals and plastic containers of blood to paper files in data warehouses. RFID antennas are now fabricated in numbers approaching millions of units per week world wide [4].

Wireless sensor networks (WSN) are also projected to expand rapidly into many applications including environmental monitoring, health and care for the aged, and security. There are predictions of very strong growth in this sector.

Almost all of the latest consumer products have a very short life (often less than one year) - not necessarily because the device has reached the end of its usable life, but because technological change is so rapid and consumer demand is such that upgrading products occurs more than once a year. Sometimes change is mandated by a change in the technology infrastructure such as new mobile telephone technologies and digital radio and television.

These trends have motivated antenna engineers to include additional constraints in antenna design beyond the RF performance characteristics. These constraints include minimal size (area and volume), minimal and low cost material usage, low energy manufacture, and ease of integration and product assembly. The antennas systems are still required to be efficient radiators in one or more bands (single band, multi-band or ultra wide band), and must have excellent impedance matching and directional properties. In the case of "smart" antennas, they must also require minimal power for beam control, and be developed as a "plug-andplay" solution for self-assembling networks. In hand-held devices and in RFID, the antenna must have a centre frequency which is relatively immune to near-by conducting and dielectric materials.

\section{NEW DESIGN METHODS}

In addressing these environmental issues, in addition to the radio frequency design requirements for mass manufacture, antenna designers must address the following issues in the mass production of antennas:

○ Material selection (conductors, dielectrics, solder, adhesives, coatings etc)

○ Design methodology (including optimisation strategies)

- Construction processes

- Recycling and reuse processes.

Design for manufacture (DfM) and design for recycling and reuse (DfR) is not a new concept in the electronics industry however Design for the Environment (DfE) has largely been overlooked [5]. It could be argued that with the new legislation, DfE has become mandatory. For these reasons, antenna design algorithms used to optimise antenna radiation performance, perhaps within a finite volume or area, should include additional parameters in the cost function used in achieving an optimal environmental design. The new design parameters might include additional characteristics such as:

○ Material properties (finite conductivity, toxicity, etc)

- Material volume

- Energy requirements for construction

- Energy requirements for recycling and reuse

Some of these issues have already been addressed to reduce manufacturing costs. For example, small antennas are a very active research topic in the antenna community [6] with applications including as computers, mobile telephone and PDA handsets become increasingly small but use an increasing number of communications radio bands.

Some of these new design issues are addressed in the following sections.

\section{CONDUCTING MATERIALS}

Copper is often the preferred material for antenna construction. It is generally easy to work in mass manufacture processes. Copper is PCB compatible, ductile, and can be readily soldered, and so planar antennas (patches, dipoles, PIFAs etc) can be manufactured at the same time as the transceiver circuits using photolithography processes.

The down-side of using PCB technologies to fabricate antennas is that the etch processing is very polluting and energy demanding. Copper is a significant pollutant in the environment and the older PCB materials contain lead, fire retardants, and other substances now banned under the RoHS directive [7].

RFID antenna technology has been directed to very low cost unit process (less than $\$ 0.20$ USD per unit). Commonly the antennas are fabricated on thin, flexible, plastic sheeting using silver, carbon, or aluminium. The common printable conductors include silver and carbon and form part of the inventory for organic semiconductor transistors [8]. More recently ink-jet printing has been suggested for both carbon and silver. These technologies present a much lower cost alternative in terms of energy and the volume of conductive material required. However, the conductivity of carbon and silver deposited as a thin film from a colloidal solution is much lower than solid metal sheeting. This problem of reduced conductivity can be solved through over printing to increase the thickness, using wider conductive tracks, and using heat curing or chemical annealing of the material after deposition. Silver, aluminium and carbon on plastic sheeting are much lower pollutants compared to copper and lead on traditional printed circuit board materials.

\section{CONDUCTOR VOLUME}

The purpose of the conductor in an antenna is to carry current. At radio frequencies, the conductor loss can play a 
major part in the overall efficiency of the antenna [9]. A strategy currently under investigation with wire antennas is to reduce the volume of conductive material by applying a closed loop design algorithm which adjusts the conductor thickness at high current areas and reduces the thickness at low current areas. As the conductive loss is proportional to the resistance squared of the antenna segment [9], one can scale the segment thickness with the current. For a dipole antenna this results in a tapered antenna with very small width at the ends and a wider conductor nearer the feed position. The design process must be iterative as a change in the conductor width in one segment results in a change in the current in every segment [10]. Within screen printing limits, this process converges and the final result is a significant reduction in the quantity of conductive material required. Other aspects of the antenna performance do not change significantly such as antenna gain, impedance and directivity.

Galehdar et al $[9,10]$ showed that the antenna efficiency $\eta$, is directly related to the resistivity $\rho$ and conductor thickness $a$ by the relationship:

$$
\eta \cong 1-C \frac{\sqrt{\rho}}{a}
$$

where $C$ is a constant which depends on the current in the conductor, the frequency of excitation and the geometry of the antenna. The antenna designer can choose an environmentally friendly conductive material with a higher resistivity (eg screen printed carbon or silver, conductive polymers etc) providing the cross-sectional area of the conductor is increased proportionally. Increasing the resistivity also has the effect of increasing the bandwidth of the antenna.

\section{CONSTRUCTION PROCESSES}

Traditional printed circuit board construction techniques require processes such as photolithography, wet etching, soldering and fitting to a prefabricated enclosure (often plastic). The process involves a number of heating steps in addition to the creation of liquid and gaseous waste. This technology is energy intensive and polluting, even with RoHS compliant technology.

In RFID, un-encapsulated silicon dies are glued to the antennas using conductive epoxy. For more complex electronic circuits, the integration of electronic devices and circuit elements into plastic with the antenna has been investigated recently [11]. The technology can employ bare die and other non-encapsulated components. This allows the design and construction of circuits using existing PCB design software with the currently available range of components [11] but with the additional possibility of using printed components such as resistors, capacitors, display technology, batteries, and transistors. With this technology, a rigid plastic circuit board containing components with screen printed tracks is fabricated using a hot embossing process. The electronic systems formed in this way can be sealed from the environment to prevent oxidation and corrosion. The sealing step removes the need for an additional enclosure. The technology also allows simple removal of the electronic components at the end-of-life. The components can then be recycled or reused. This eliminates the need for circuit board shredding, incineration and then metal retrieval, or the shipping of e-waste to third world countries where hand removal presents a significant hazard to the workers engaged in this industry $[12,13]$.

The RF characteristics of printed antennas on very thin, flexible, substrates introduces an additional problem to antenna designers. That is, the antenna is likely to be bent during normal operations. Bending a planar antenna can shift the resonant frequency both up and down $[14,15]$. This can be overcome by designing the antenna for an increased bandwidth.

The effect of the surrounding material (backing material) on antenna performance is also the subject of much research [16]. There is therefore an emphasis in increasing the bandwidth of the antennas. This is commonly achieved by using slot antennas, wider conductive tracks, parasitic tracks and triangular structures at the ends of the dipole.

\section{Planar ANTENNA Design Methods}

There are three basic designs for printed antennas patches, slots and wires [17]. All can be modified by the use of parasitic elements and multiple feed points. Patches usually require a ground plane for operation and have a narrow bandwidth. Slots normally have a wider bandwidth, but require the area of the antenna to be coated with conducting material. Both slots and wire antennas do not normally require a ground plane. Printed wire antennas require the smallest volume of conductive material and so are preferred from an environmental perspective.

Multi-band and broad band antennas are often designed using a patch with slots and stubs to create additional resonant frequencies or increased bandwidth when these frequencies are over lapping [14]. While slot antennas can be designed for multi-band operation, this is less common. Recently multiband wire antennas with a number of notches have been designed using optimisation techniques [18].

Given the task of designing small antennas for multi-band operation and sustainability, the most logical starting point is the meander wire structure, and significant work has been dedicated to optimising such structures for both antenna performance and material usage [19].

\section{CONCLUSIONS}

The concept of designing antennas for mass manufacture requires recognition of the environmental impacts of the design method, the materials and the fabrication technique employed. In this paper, a number of emerging technologies have been discussed which are compliant to these environmental standards. In many cases the manufacturing requirements are relatively energy efficient and the generation of waste is small. Regardless of the current concern about global warning and the introduction of a carbon tax on energy consumption, it makes economic sense to use sustainable design and manufacturing technology for the mass manufacture of antennas. There is merit in antenna designers incorporating these new requirements into their designs. 


\section{ACKNOWLEDGMENTS}

The author has drawn much of this material from colleagues in the Centre for Wireless Monitoring at Griffith University. In particular, Amir Galehdar and Neeli Madhusudanrao have made major contributions to this paper. The author also thanks his colleague Dr Sunil Herat for his contributions to the environmental arguments included in this paper. Griffith University is a member of StEP.

\section{REFERENCES}

[1] M. Goosey, "End-of-life electronics legislation - an industry perspective," Circuit World, vol. 30 (2), pp. 41-45, 2004

[2] A. Gottberg, J. Morris, S. Pollard, C. Mark-Herbert and M. Cook, "Producer responsibility, waste minimisation and the WEEE directive: Case studies in eco-design from the European lighting sector," Science and the Total Environment, vol. 359, (1-3), pp 38-56, April 2006.

[3] R. Kuehr, "Terms of Reference", StEP TF1, http://www.stepinitiative.org/, accessed 25 Oct 2008.

[4] N.C. Wu, M.A. Nystrom, T.R. Lin, and H.C. Yu, "Challenges to global RFID adoption”, Technovation, vol. 26, pp. 1317-1323, 2006.

[5] L.H. Goldberg, and W. Middleton (eds), Green electronics, green bottom line: environmentally responsible engineering, Newnes, Boston, 2000.

[6] IEEE APS Symposium Digest of Papers, San Diego, July 2008.

[7] Q. Gan, "A case study of microwave processing of metal hydroxide sediment sludge from printed circuit board manufacturing wash water," Waste Management, vol. 20, pp. 695-701, Dec. 2000.

[8] A. Knobloch, A. Bernds, and W. Clemens, "Printed polymer transistors," $1^{\text {st }}$ Int. IEEE Conf. on Polymers and Adhesives in Microelectronics and Photonics, pp. 84-90, 2001.

[9] A. Galehdar and D.V. Thiel, "Antenna efficiency calculations for electrically small RFID antennas," IEEE Antennas and Wave Propagation Letters, vol. 6, pp. 156-159, 2007.

[10] A. Galehdar, D.V. Thiel, and S.G. O'Keefe, "Tapered wire antenna design for maximum efficiency and minimal environmental impact," ISAPE'08, Kunming, China, Nov. 2008.

[11] D.V. Thiel and M. Neeli, "Fabrication of electronic components in plastic," WO Patent WO/2007/002995, July 2006.

[12] S. Herat, "Sustainable management of electronic waste: e-waste", Clean Soil Air Water, vol. 35(4), pp; 305-310, Sept. 2007.

[13] C.S.C. Wong, S.C. Wu., N.S. Duzgoren-Aydin, A. Aydin and M.H. Wong, "Trace metal contamination of sediments in an e-waste processing village in China," Environmental Pollution, vol. 145 (2), pp. 434-442, Jan. 2007.

[14] A. Galehdar and D.V. Thiel, "Flexible lightweight antenna at $2.4 \mathrm{GHz}$ for athlete clothing," IEEE APS Symposium, Honululu, pp. 4160-4163, June 2007.

[15] P. Salonen and Y. Rahmat-Samii, "Textile antennas: Effects of antenna bending on input matching and impedance bandwidth," IEEE Aerospace \& Electronic Systems Mag., vol. 22 (12), pp. 18-22, Dec 2007.

[16] D.M. Dobkin, and S.M. Weigand, "Environmental effects on RFID tag antennas," IEEE MTT Symposium, pp. 135-138, June 2005.

[17] K.V.S. Rao, P.V. Nikitin, and S.F. Lam, "Antenna design for UHF RFID tags: a review and a practical application," IEEE Trans. Antennas and Propagation, vol. 53 (12), pp. 3870-3876, Dec. 2005.

[18] Z. Bayraktar, P.L. Warner, and D.H. Warner, "Reconfigurable high gain stub-loaded monopoles," IEEE APS Symposium, San Diego, July 2008

[19] M. Randall, A. Lewis, A. Galehdar, and D. Thiel, "Using ant colony optimization to improve efficiency of small meander line RFID antennas," IEEE Int. Conf. on e-Science and Grid Computing, pp. 345351, Dec 2007. 